\title{
Higher levels of dynamin-related protein 1 are associated with reduced radiation sensitivity of glioblastoma cells
}

Chiung-Chyi Shen ( $\nabla$ ccshen61093@gmail.com )

Taichung Veterans General Hospital https://orcid.org/0000-0002-9622-7394

\section{Wen-Yu Cheng}

Institute of Biomedical Sciences, National Chung Hsing University

\section{Kuan-Chih Chow}

Gradauate Institute of Biomedical Sciences, National Chung Hsing University

\section{Ming-Tsang Chiao}

Neurological Institute Head of Department of Neurosurgery Taichung Veterans General Hospital

Yi-Chi Yang

Neurological Institute Head of Department of Neurosurgery Taichung Veterans General Hospital

\section{Research article}

Keywords: DRP1, glioblastoma multiforme, radiation resistance, autophagy, DNA repair, nuclear transport

Posted Date: March 23rd, 2020

DOI: https://doi.org/10.21203/rs.2.18627/v3

License: (9) This work is licensed under a Creative Commons Attribution 4.0 International License. Read Full License 


\section{Abstract}

Background : Dynamin-related protein 1 (DRP1) is a GTPase involved in mitochondrial fission, mitochondrial protein import, and drug sensitivity, suggesting an association with cancer progression. This study was conducted to evaluate the prognostic significance of DRP1 in glioblastoma multiforme (GBM).

Methods : DRP1 expression was measured by immunohistochemistry and Western blotting. Correlations between DRP1 expression and clinicopathological parameters were determined by statistical analysis. Differences in survival were compared using the log-rank test.

Results : DRP1 expression was detected in $87.2 \%(41 / 47)$ of the investigated patients with GBM. The patients with higher DRP1 levels had worse survival ( $p=0.0398)$. In vitro, the silencing of DRP1 reduced cell proliferation, invasive potential, and radiation resistance. The addition of shikonin inhibited DRP1 expression and increased drug uptake. Moreover, shikonin reduced the nuclear entry of DNA repairassociated enzymes and increased radiation sensitivity, suggesting that reducing DRP1 expression could inhibit DNA repair and increase the radiation sensitivity of GBM cells.

Conclusions : Our results indicate that DRP1 overexpression is a prospective radio-resistant phenotype in GBM. Therefore, DRP1 could be a potential target for improving the effectiveness of radiation therapy.

\section{Background}

Glioblastoma multiforme (GBM, Word Health Organization grade IV glioma) is the most aggressive adult brain tumor and thus has the worst prognosis. Most GBM patients $(\sim 70 \%)$ die within two years of being diagnosed [1]. Upon initial diagnosis of GBM, standard treatment consists of maximal surgical resection, radiotherapy, and adjuvant chemotherapy with temozolomide (TMZ) [2]. Proper radiation therapy for GBM consists of fractionated conformal three-dimensional radiotherapy to a total dose of $60 \mathrm{~Gy}$ in 30 daily fractions of 2 Gy each was delivered. Such therapy, with the pre-radiation intake of an alkylating agent, TMZ, has improved treatment efficacy. However, the effects remain limited [3].

Recent research in the field of molecular biology have strongly suggested that GBM is associated with the gain of oncogene function (e.g., $N$-ras, human epidermal growth factor receptor [EGFR]-1 [HER-1, also known as v-ErbB-2 avian erythroblastic leukaemia viral oncogene homolog 1, erbB-1] and isoforms 1 and 2 of citrate dehydrogenase [IDH1/2]) [4, 5]; as well as the loss or inactivation of the function of tumor suppressor genes (e.g., p53, RB1, $0^{6}$-methylguanine-DNA-methyltransferase [MGMT], and phosphatase and tensin homolog [pTEN]) [6-9]. Although their oncogenic consequences have yet to be fully determined, lifestyle-related risk factors (e.g., smoking, drinking habits and compulsive use of wireless phones) and environmental risk factors (e.g., exposure to ionizing radiation and chemicals) have been implicated in cumulative multigene alterations, which can then activate oncogene expression, induce aberrant cell growth and accelerate carcinogenic changes [10-14]. EGFR expression in GBM has been investigated in several provisional clinical trials that examined the EGFR-phosphatidylinositol 3-kinase 
(PI3K)-Akt/protein kinase B (PKB) and mammalian targets of rapamycin (mTOR) signaling pathways [1517]. Although the first set of preliminary results were promising; however, improvements in clinical treatment efficacy and patient survival were not as evident in the final results.

Hypoxia is an important factor in the increased GBM resistance simply through its induction of autophagy [18]. Biochemically, hypoxia not only activates the nuclear translocation of an apoptosisrelated mitochondrial protein, BCL-2 nineteen kilodalton interacting protein 3 (BNIP3) [19, 20], but also elevates the synthesis of a-ketoglutarate and 2-hydroxyglutarate by IDH to increase chromatin epigenetic modification [21, 22], as well as resistance to treatment with $\operatorname{TMZ}$ and radiation $[3,9,23]$. Hypoxia also induces the nuclear translocation of dynamin-related protein 1 (DRP1), which is associated with a DNA repair-related protein, human homolog of yeast Rad23 protein A (hHR23A), through which DRP1 can, on one hand, protect nucleoli and, on the other hand, increase the DNA repair as well as cisplatin resistance of cancer cells $[24,25]$. In addition, HIF-1alpha also modulated mitochondrial dynamics under hypoxia by directly regulating the expression of Drp1 [26]. Treatment with mitochondrial division inhibitor-1 (Mdivi-1), a specific inhibitor of DRP1-mediated mitochondrial fission, significantly suppressed hypoxia-mediated pancreatic beta-cell death in vitro [27]. Therefore, abnormal mitochondrial dynamics could be a marker for the early diagnosis of molecular and monitoring disease progression [26].

DRP1 is an $80-\mathrm{kDa}$ GTPase, that mediates the budding and scission of a variety of transport vesicles and organelles [24, 28, 29], including mitochondria [30]. A number of anticancer drugs, e.g., epipodophyllotoxins and cisplatin, induce mitochondrial fragmentation, a phenomenon that is closely associated with apoptosis and chemotherapeutic cytotoxicity [31]. A reduction in the levels of DRP1 protein/ transcript causes ATM-dependent G2/M arrest and aneuploidy [32]. Disturbance in mitochondrial dynamics is due to an increased expression of Drp1 fission protein in vitro and in vivo [33]. A better understanding of DRP1 on drug activity could, therefore, provide more valuable information to improve disease management. In addition, the aforementioned chemotherapeutic agents might become vital probes for studying the essential function as well as the regulation mechanisms of DRP1 and other fusion/fission-related proteins in intracellular material transport and organelle damage [24, 25, 28, 29]. However, the role of DRP1 in GBM has not previously been studied.

In this study, therefore, we used immunohistochemistry and Western blotting to determine DRP1 expression in GBM. We then evaluated the prognostic significance of DRP1 expression in GBM patients. Moreover, we investigated the effect of shikonin and suberoylanilide hydroxamic acid (SAHA, vorinostat), a histone deacetylase (HDAC) inhibitor, on DRP1 expression as well as radiation sensitivity in vitro.

\section{Methods}

The protocols of this study were approved by the Medical Ethics Committee of Taichung Veterans General Hospital (Approval number: CF12026B\#2).

\section{Tissue specimens and immunohistochemical detection of DRP1 expression.}


The validation cohort consisted of 47 cases selected from the primary cohort based on the following criteria: (1) available follow-up data and samples and (2) a post-operative survival time of more than 1 month. From January 2008 to August 2012, tissue specimens were collected from 47 patients with newly diagnosed GBM. Exclusion criteria: 1. GBM patients with unconfirmed pathology, 2. GBM patients with spinal involvement, 3. GBM patients with incomplete data records. The obtained samples were frozen immediately after surgery with prior consent from the patients. Tissue microarrays of 35 American GBM samples (GL806, US Biomax, Inc., Rockville, MD, USA) were used to compare DRP1 expression between Taiwanese and American patients. Immunohistological staining was performed on formalin-fixed sections using an LSAB method (DAKO, Carpenteria, CA). The chromogenic reaction was visualized by peroxidase-conjugated streptavidin and aminoethyl carbazole (Sigma, St. Louis, MO) [24, 28, 29, 34, 35]. Slides were evaluated by at least two independent pathologists without knowledge of the given patient's clinicopathological background. An immune-reaction of the histological scoring system was used for scoring [36]. DRP1 expression was assessed in the non-necrotic tumor areas of five separate microscopic fields of view under a magnification of $40 \mathrm{X}$ and was classified as the mean of the percentage of DRP1 immunohistochemical positive tumor cells. DRP1 expression was ranked according to the following percentage ranges: $<25,25-50,51-75$, and $>75 \%$ DRP1-positive tumor cells. The associated kappa statistics revealed a good interobserver agreement of $k=0.81$. A specimen was considered to have strong signals when more than $50 \%$ of the cancer cells were positively stained; intermediate signals, if $25-50 \%$ of the cells were positively stained; weak signals if the percentage of positively stained cells was between 10 and $25 \%$; and negative signals if less than $10 \%$ of the cells were positively stained. Cases with strong and intermediate signals ( $\geq 25 \%$ cells positive) were classified as $\mathrm{DRP} 1^{+}$, while those with weak or negative DRP1 signals were classified as DRP1 ${ }^{-}$.

\section{Cell culture and alteration of DRP1 expression using lentivirus-carrying shRNA or ectopic plasmid.}

The human GBM cell lines, H4, U87MG, and T98G were obtained from ATCC (Manassas, VA, USA) and grown in Dulbecco modified Eagle medium (DMEM) supplemented with 10\% fetal bovine serum (FBS), 4 $\mathrm{mM}$ glutamine, $100 \mathrm{U} / \mathrm{ml}$ penicillin and $100 \mu \mathrm{g} / \mathrm{ml}$ streptomycin. The cells were routinely tested and authenticated using a PromegaGenePrint ${ }^{\circledR} 10$ system for human cell line DNA typing (Mission Biotech, Taipei, Taiwan). Among these three cell lines (H4, T98G, and U87 cells), the U87MG and T98G cells have been proven have lineages consistent with those of human glioblastoma U87MG and T98G cells treated with short tandem repeat (STR) assay performed by a third-party research institution, while such testing was not performed for the H4 cells (Supplementary Figs. S6 \& S7). The cells were grown to $80 \%$ confluence on the day of infection. Lentivirus carrying DRP1 shRNA was prepared using a three-plasmid transfection method [37]. The product lentivirus was used to infect U87MG and T98G cells, and cells with DRP1 gene knockdown (DRP1 ${ }^{\mathrm{KD}}$ ) were selected using $1 \mu \mathrm{g} / \mathrm{ml}$ puromycin. After lentivirus infection including infection with sh-Luc and DRP-1 ${ }^{\mathrm{KD}}$, the attached cells were detached by treatment with trypsin and reseeded at $100,500,2,000$, and 5,000 cells/well of culture plate, respectively. The cells were incubated at $37^{\circ} \mathrm{C}$ for 10 days, visible colonies that contained more than 50 cells were counted and the plating efficiency was determined. A semi-log graph of the cell survival fractions (that is, the ratio of 
colonies formed by lentivirus-infected cells to colonies formed by control cells) against radiation dosage was plotted (Fig. 2C).

\section{Western blotting analysis.}

The protocols for western blotting analysis have been described previously [24, 28, 29, 34, 35]. Briefly, 30 $\mu \mathrm{g}$ of total cell lysate was separated on a $10 \%$ polyacrylamide gel with a $4.5 \%$ stacking gel. After electrophoresis, proteins were transferred to a nitrocellulose membrane. The membrane was probed with specific antibodies. The proteins were visualized by exposing the membrane to an X-Omat film with enhanced chemiluminescence reagent (Merck, Darmstadt, Germany). The respective primary antibodies were mouse anti-DRP1 and mouse anti-b-actin. These mouse monoclonal antibodies to DRP1 were homemade and have previously been characterized [24]. The digital images on X-Omat film were processed in Adobe Photoshop 7.0 (http://www.adobe.com/). The results were analyzed and quantified by the Image J software program ( $\mathrm{NIH}$, Bethesda, MD).

\section{Confocal immunofluorescence microscopy.}

Purified shikonin (>98\%, HPLC) was purchased from Sigma-Aldrich (Saint Louis, Mo). The method for immunofluorescence confocal microscopy has been described previously [24, 28, 29]. Briefly, the cells on slides were fixed with $4 \%$ paraformaldehyde for $15 \mathrm{~min}$ at room temperature and permeabilized with $0.1 \%$ Triton X-100 prior to staining with mouse anti-DRP1. After washing off of the primary antibodies, the slides were incubated with Alexa 488-conjugated goat anti-rabbit IgG (Invitrogen, Grand Island, NY). The nuclei were stained with 4', 6-Diamidino-2-phenylindole (DAPI), and the slides were examined under a laser confocal microscope (Olympus FV-1000, Tokyo, Japan). Images of the cells were analyzed using the FV10-ASW 3.0 software (Tokyo, Japan).

\section{Colony formation assay and the culture of GBM stem cells.}

T98G-shLuc and T98G-DRP1 ${ }^{\mathrm{KD}}$ cells, U87-shLuc and U87-DRP1 ${ }^{\mathrm{KD}}$ cells, and GSC-shLuc and GSC-DRP1 ${ }^{\mathrm{KD}}$ cells, were separately treated with 3,6, or 12 Greys (Gy) of radiation (Varian 21EX linear accelerator, Varian Oncology Systems, Palo Alto, CA). For colony formation assays, after radiation or infection with a lentivirus, the attached cells were detached by treatment with trypsin and reseeded at 100,500, 2,000, and 5,000 cells/well of culture plate, respectively. The cells were incubated at $37^{\circ} \mathrm{C}$ for 10 days, visible colonies that contained more than 50 cells were counted and the plating efficiency was determined. Semilog graphs of the cell survival fractions (that is, the ratio of colonies formed by irradiated cells to colonies formed by control cells) against radiation dosage was plotted. The GSCs were prepared according to the previously described protocol [38]. In brief, the obtained tissues were washed and enzymatically dissociated into individual cells. The dissociated cells were cultured in neurosphere-conditioned medium using Neurobasal media (Invitrogen, 21103-049) containing N2 and B27 supplements (Invitrogen, 17502048; 0080085SA), plus human recombinant bFGF and EGF (50 ng/ml each; R\&D Systems, 233-FB; 236EG). After 2 to 4 weeks incubation, serial dilution was performed on the surviving GSCs to select a single 
cell that was able to grow a new sphere. The glioblastoma stem cells (GSCs), spheroid type, were cultured in neurosphere-conditioned medium (NSC medium).

\section{The cell mobility of cells across Matrigel assay.}

The cell mobility of infected lentiviruses including both shLuc and DRP-1KD in U87MG and T98G cells was measured with at the modified Boyden chamber containing Matrigel gel (BD Biosciences, USA) [39], with the well of the chamber containing a membrane with $8 \mu \mathrm{m}$ pores. The Matrigel assay was performed according to the protocol suggested by BD Biosciences. Briefly, a vial of BD MatrigelTM Basement Membrane Matrix (BD-MBM, 356234) was thawed on ice overnight, and then diluted to $1 / 2$ and $1 / 4$ with icecold serum-free Dulbecco's modified Eagle's medium (DMEM). Five ml of the diluted BD-MBM was spread in a petri dish on ice, before a piece of polycarbonate membrane (with $5.0 \mu \mathrm{m}$ pore size) was submerged into the suspension mixture. Membrane coating was performed at room temperature for one hour. The membrane was rinsed with serum-free DMEM once and then placed into the Boyden chamber.

The lower chamber contained the $4 \%$ FBS medium. $1 \times 10^{5}$ cells were pipetted into the well of the upper chamber at intervals of one $\mathrm{hr}$ for $8 \mathrm{hr}$ and then incubated at $37^{\circ} \mathrm{C}$ for $24 \mathrm{hr}$ in a humidified incubator with $5 \% \mathrm{CO}_{2}$. Following complete removal of the non-invading cells, the membrane was lifted from the chamber, and fixed in $100 \%$ methanol for 2 min. The cells on the membrane were stained with $1 \%$ toluidine blue for $2 \mathrm{~min}$ and washed twice with distilled water. After counting the cells, the percent invasion on the membrane was calculated by comparing the experimental group to the control group.

To count the cells in the lower chamber, the medium was carefully removed, and replaced with $100 \mu$ of PBS with WST-1 (BioVision, Mountain View, CA) solution. The reaction was incubated at $37^{\circ} \mathrm{C}$ for $1-4 \mathrm{hr}$ in a humidified incubator with $5 \% \mathrm{CO}_{2}$. Each experiment was done in triplicate, and the optical absorbance (450/620, in a SunriseTM, Tecan, microplate absorbance reader) was measured by coloration of the reacted substrate, which was catalyzed by mitochondrial dehydrogenases. The percent invasion and invasion index in the chamber were calculated by comparing the experimental group to the control group.

A polycarbonate membrane without Matrigel coating was used to conduct the cell transfer study.

\section{Drug sensitivity assay.}

Drug-sensitivity was measured by a WST-1 assay [40]. Cells were seeded at 100, 1,000, and 5,000 cells/96-well plates $18 \mathrm{hr}$ prior to drug challenge. Cells were pulse-treated with $4 \mu \mathrm{M}$ of daunorubicin for 2 $\mathrm{hr}$. The negative control cells were treated with the solvent for the drug. Total survival of the cells was determined at $72 \mathrm{hr}$ after the drug challenge, and percent survival was estimated by dividing the optical absorbance resulting from each experimental group with that of the control group. Each experiment was done in triplicate, and the optical absorbance was measured by the coloration of the reacted substrate, WST-1 (BioVision, Mountain View, CA), which was catalyzed by mitochondrial dehydrogenases.

\section{Statistical analysis.}


Overall survival (OS) was defined as the time from the date of diagnosis to the date of death. Survival curves were plotted using the Kaplan-Meier estimator [41] and the statistical difference in survival between the different groups was compared by a log-rank test [42]. Statistical tests were two-sided, and $p$ $<0.05$ was considered significant. The $t$-test was utilized to compare the numerical differences in clinical parameters. Differences in patients' performance status, tumor location, and surgical resection status were assessed by c-square or Fisher's exact test. Analyses of the data were performed using SPSS 10.3 software (Chicago, IL).

\section{Results}

\section{GBM specimens show higher levels of DRP-1}

From January 2008 to August 2012, 47 GBM patients who had undergone standard surgery and palliative radiation therapy with daily TMZ $\left(75 \mathrm{mg} / \mathrm{m}^{2}\right)$ adjuvant to monthly TMZ $\left(150-200 \mathrm{mg} / \mathrm{m}^{2}\right)$ were retrospectively enrolled in the study. The demographic characteristics and treatment parameters of these patients are listed in Table 1. The identification and classification of tissue staining are described in detail in the Methods section. Using immunohistochemical staining, the expression of DRP1 was detected in 41 (87.2\%) of the collected Taiwanese GBM tumor specimens (Fig 1A, where DRP1 is shown as crimson precipitates in the cytoplasm), and some DRP1 was identified in the nuclei of tumor cells (Fig. 1B, where DRP1-positive nuclei are shown as brown precipitates in the nuclei, compared to DRP1-negative blue nuclei) in $33(80.5 \%)$ of the 41 samples. The positive and negative staining controls are shown in Supplementary Figs. S4A-S4C DRP1 signal was detected in 32 (91.4\%) of 35 American GBM patients, and nuclear DRP1 (DRP1 ${ }^{\text {nuc }}$ ) was detected in $27(84.4 \%)$ of the corresponding 32 specimens. No difference was found in DRP1 expression between the American and Taiwanese GBM patients $(p=0.609)$. The expression of the 80-kDa DRP1 in Taiwanese patients was confirmed by Western blotting (Fig 1C). In addition, we speculated that the protein of DRP1 in the DRP1-positive nuclei was likely to consist of the phosphorylated state of DRP1 (Supplementary Fig. S2C). Interestingly, the molecular weights of the DRP1 in 7 of 12 surgical specimens were higher than the anticipated $80-\mathrm{kDa}$ and three samples clearly had two protein bands, indicating that the DRP1 in biopsies could be post-translationally modified [24]. It is worth mentioning that the anti-DRP1 monoclonal antibody has been proved and characterized, and is a highly specific antibody [24].

\section{The impact of DRP1 overexpression on GBM patient prognosis}

The survival of patients with low DRP1 levels was significantly better than that of patients with high DRP1 levels, and the difference in cumulative overall survival (OS) $[p=0.0398,95 \%$ confidencel interval (Cl), 1.051-8.151; Hazard ratio (HR) between DRP1 ${ }^{+}$and DRP1- patients was 5.71] was significant (Supplementary Figs. S1A \& S1B). The actual 18 -month OS rate of DRP1 ${ }^{+}$patients was $40.0 \%$, while that of DRP1- patients was $80.0 \%$. When nuclear DRP1 was used as a perspective parameter, the survival of patients with nuclear DRP1 was significantly worse than that of the other two groups (Fig 1D, $p=0.0183$, log-rank test for trend; or Supplementary Figs. S1C \& S1D, OS, $p=0.0039$, and PFS, $p<0.0001$ ), indicating 
that the expression of DRP1, including nuclear DRP1, could act as a prognostic phenotype of GBM. Subgroup analyses revealed that GBM patients with DRP1 overexpression and unmethylated MGMT promoter had the worst radiation responses and survival (Supplementary Figs. S1E \& S1F). At the time of data analysis (patients had been routinely followed for up to 24 months), 5 (83.3\%) of 6 DRP1- patients were alive. Among those 5 patients, four were progression-free.

\section{Silencing of DRP1 expression in GBM cells decreases cell growth and mobility, but increases radiation sensitivity}

In vitro, the protein levels of DRP1 were examined by Western blotting analysis in three human glioma cell lines (H4, U87MG, and T98G). All three cell lines expressed both 80- and 85-kDa proteins (Fig. 2A). Both the $80-\mathrm{kDa}$ and $85-\mathrm{kD}$ a proteins were DRP1 proteins and that the $85-\mathrm{kD}$ a protein could be posttranslationally modified (Supplementary Figs. S2A-2D). Furthermore, in the presence of calf intestinal phosphatase (CIP), the $85-\mathrm{kD}$ a protein band gradually disappeared, but the levels of the $80-\mathrm{kD}$ a protein band increased, suggesting that the $85-\mathrm{kD}$ a protein could be a phosphorylated form of $80-\mathrm{kDa}$ DRP1 (Supplementary Fig. S2).

As noted above, both pathological and clinical studies have shown that higher DRP1 expression is correlated with worse prognosis in patients concurrently treated with TMZ and irradiation [43, 44]. Therefore, we examined the effect of DRP1 on cell proliferation and migration. In vitro, the inhibition of DRP1 expression caused by using shRNA to knockdown DRP1 expression (DRP1 ${ }^{\mathrm{KD}}$ ) (Fig. 2B) reduced the cell growth (Fig. 2C) and mobility of tumor cells across Matrigel (Fig. 2D). Meanwhile, the decrease of cell mobility after lentivirus infection was not associated with cell viability. This was because the cell mobility assay used stable clones of lentivirus-infected cells, while the colony formation assay used cells following their infection with shLuc or DRP-1KD lentivirus.

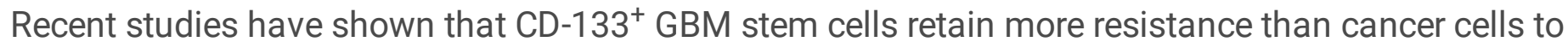
ionizing radiation $[45,46]$. The silencing of $\mathrm{DRP} 1$, on the other hand, increased the radiation sensitivity of both T98G (Fig. 3A) and U87 cells (Fig. 3B). The addition of TMZ only increased the radiation sensitivity of $\mathrm{DRP} 1^{\mathrm{KD}}$ T98G cells. The decrease in radiation resistance was by about 5-10 fold. Interestingly, CD-133 ${ }^{+}$ GBM stem cells (GSC) also highly expressed DRP1, in particular the 85-kDa protein (Fig 3C). The silencing of DRP1 expression inhibited the cell growth of GSCs, including the number of cells and the spheroid formation (Fig 3D). These results confirmed our previous findings that DRP1, which is essential for mitochondrial protein import, is involved in cell growth and genotoxic resistance [24, 28, 29], suggesting that reducing the total intracellular DRP1 expression or nuclear DRP1 levels could enhance the anticancer efficacy of radiation and anticancer drug therapies.

\section{The respective effects of shikonin and SAHA on DRP1 expression and cell survival}

Our previous studies showed that DRP1 is involved in an alternative mitochondrial import route, and the disruption of this route induces autophagy $[28,29]$. Using DRP1 as a target, we found that several Chinese medicinal herbal extracts (CMHEs) inhibit DRP1 expression, including Astragalus, propinquus, 
Koelreuteria elegans, Lithospermum erythrorhizon, and Polygala tenuifolia [47]. Using a search engine (https://www.ncbi.nlm.nih.gov/pmc/articles/PMC5664208/) to search for the major ingredients of the plants, we found that shikonin from $L$. erythrorhizon is one of the most promising pure compounds [48]. To evaluate the effects of shikonin and DRP1 protein on the process of autophagy and apoptosis, we analyzed the related protein expression.

As shown in Fig. 4A, shikonin decreased the levels of both 80- and 85-kDa DRP1 and increased that of an autophagic marker, LC3B-II. Using fluorescence microscopy, we found that shikonin clearly induced the formation of autophagosomes (Fig. 4B). Although SAHA did not affect DRP1 expression (Fig. 4C), it clearly increased levels of poly [ADP-ribose] polymerase 1 (PARP-1), a marker of apoptosis (Fig. 4D, upper panel), but did not induce cleavage of PARP-1.

In DRP1 ${ }^{\text {KD }}$ T98G cells, SAHA increased PARP-1 cleavage (Fig. 4D, right-hand side) as well as cell death (Fig. 4E right panel) and mitochondria depolarization [Fig. 4E left panel, as shown by changes of mitochondrial membrane potential (MMP)]. After SAHA treatment, T98G cells were harvested and respectively analyzed by Western blotting and flow cytometry. The expression of b-actin was used as a monitoring standard for relative protein expression in the Western blotting analysis. Results are the means \pm S.D. of three independent experiments, where $* *$ indicated $p<0.001$.

\section{Shikonin increases nuclear levels of anticancer drugs and arrest of DNA repair-related proteins in the perinuclear MAM}

Our previous studies showed that inhibiting intracellular cargo transportation-related enzymes could result in a reduction of nuclear levels of DNA repair-related proteins, such as ataxia-telangiectasiamutated (ATM) kinase, and an increase in the cytotoxic effects of anticancer drugs and irradiation [24, 28, $29,49]$. Interestingly, using an Operatta ${ }^{\circledR}$ high content imaging system (PerkinElmer, Waltham, MA) to examine the effect of shikonin on the nuclear levels of 4',6-diamidino-2-phenylindole (DAPI) and daunorubicin levels, in T98G cells, we found that shikonin not only markedly increased nuclear DAPI and daunorubicin, but also significantly increased cell sensitivity to daunorubicin (Figs. 5A-5C). We further found that glioblastoma cells are sensitive to daunorubicin even through it is not used for brain tumors. Moreover, shikonin treatment reduced the nuclear accumulation of ATM (Fig. 5D, left panel), supporting our previous results indicating that the inhibition of DRP1 expression restricted the nuclear import of DNA repair-related enzymes and induced bulging of the MAM (Fig. 5D, right panel). Using a transmission electron microscope, we further showed that shikonin treatment increased nuclear envelope damage (Figs. 5E1 \& 5E2). Shikonin causes nuclear envelope breaks (Fig. 5e2, arrow), and leads to the disruption of the inner and outer nuclear membrane in T98G cells, which implies that membrane disintegration starts after the addition of shikonin.

\section{Discussion}


Our results showed that DRP1 was highly expressed in the investigated newly diagnosed GBM patients $(87.2 \%, 41 / 47)$. Moreover, nuclear DRP1 was identified in $33(80.5 \%)$ of the DRP1-positive (DRP1 ${ }^{+}$) pathological specimens. Using Western blotting to analyze DRP1 expression, we found that the molecular weights of DRP1 in 10 of 12 surgical samples were around $85-\mathrm{kDa}$. In spite of the number of analyzed patients being less, these results still moderately indicated that the DRP1 found in GBM biopsy tissues could be post-translationally modified $[18,24]$. Statistical analyses showed that patients with DRP1 overexpression or nuclear DRP1 $\left(\mathrm{DRP}^{\mathrm{nuc}}{ }^{\mathrm{nu}}\right)$ were more resistant to radiation and hence had a higher frequency of disease relapse and worse prognosis. Subgroup statistical analyses further revealed that GBM patients with DRP1 overexpression and unmethylated MGMT promoter had the worst radiation responses and survival (Supplementary Figs. S1E \& S1F).

In vitro, DRP1 expression correlates with resistant phenotype to radiation and TMZ (T98G cells were more resistant than U87MG cells). Nonetheless, the silencing of the DRP1 gene increases the sensitivity of both U87MG cells (with a methylated MGMT promoter) and T98G cells (with an unmethylated MGMT promoter) to radiation and TMZ, suggesting that the expression of DRP1, as well as that of Aldo-keto reductase (AKR) $1 \mathrm{C} 1$ and $1 \mathrm{C} 2[49,50]$, increases their resistance to radiation to yield the radiationresistant phenotype of GBM cells [24, 28, 29,34,35]. The binding of DRP1 to the nucleoli could further protect the rRNA-encoding region to maintain genome stability [24], and these events together could regulate cellular activity against cytotoxic agents and radiation. On the other hand, nuclear phosphorylated DRP-1 is likely to exhibit increased protein expression under hypoxia (Supplementary Fig. S2C), as well as increased drug resistance [24].

Interestingly, a previous study reported that long-term exposure of GBM cells to TMZ decreases drug sensitivity by up-regulating the expression of AKR enzymes and glucose transporter [51]. The elevation of glucose transport altered mitochondrial metabolism, while the increase of AKR enzymes deactivated TMZ and cisplatin, supporting our finding that some AKR enzymes were localized on the mitochondriaassociated membrane (MAM), the essential organelle that regulates material transport to the mitochondria and nucleus $[47,49]$. Both transportation passages require DRP1, ATAD3A, and mitofusin 2 (Mfn2) $[28,29]$. Since shikonin inhibits DRP1 expression in T98G cells, it is reasonable to believe that intracellular materials, such as proteins and lipids which are synthesized in the endoplasmic reticulum (ER) and then scheduled to be transported to the mitochondria and nucleus [24, 29], will be accumulated in the MAM. The lack of a timely supply of such materials would make it difficult to maintain mitochondrial integrity, which could severely diminish the mitochondrial function and change the organelle morphology (Supplementary Figs. S3A-S3D).

It is worth noting that mitochondria do not synthesize phosphatidylserine (PS) per se. Rather PS is mainly synthesized in the ER and MAM, and then imported to the mitochondria. In contrast phosphatidylethanolamine (PE), the unique phospholipid that is conjugated to autophagy-related gene 3 (Atg3) during the initiation of autophagy, is converted from the PS in the mitochondria and transported back to the ER. Interestingly, the ER also constitutes the outer part of the nuclear envelope. It is, therefore, reasonable to anticipate that a decrease of cytoplasmic DRP1 may concurrently damage the 
mitochondrial membrane and the nuclear envelope, which would not only decrease the general ATP supply but also reduce nuclear imports of DNA repair-related enzymes [49]. Moreover, elevated nuclear import of DRP1 could consume massive amounts of intracellular hHR23A, which would competitively diminish the nuclear import of xeroderma pigmentosum complementation group $C$ (XPC) to delay the nucleotide excision repair (NER) that is essential for maintaining genome integrity following the challenge of TMZ or cisplatin [24, 49, 51, 52].

Both TMZ and radiation induce nuclear and mitochondrial genome DNA breakage. TMZ affects both mitochondrial electron transport and oxidative phosphorylation [53]. Radiation, on the other hand, induces the translocation of ATM, which is important for the repair of DNA breaks, to the nucleus and mitochondria [54]. An ATM deficiency, whether induced by a genetic or a biochemical method, reduces genomic DNA repair functions as well as mitochondrial biogenesis and oxidative respiratory functions [55]. By demonstrating that extranuclear ATM is bound to ER-associated peroxisome targeting signal type 1 (PTS1) receptor (also named peroxisomal biogenesis factor 5, Pex5), Watters et al suggested that besides the nucleus, ATM could be targeted to the MAM [56]. In a gene knockout study, Baumgart et al further showed that a defect in the Pex5 gene reduced peroxisomal metabolism, as well as the expression and activities of the mitochondrial respiration system [57]. Their results strongly suggested that MAM and its associated enzymes, in particular, DRP1, a GTPase, play a pivotal role in allocating materials, that are essential for maintaining organelle morphology, as well as the DNA integrity of the genome and the mitochondria. Our data supported their results and showed that reducing cytoplasmic DRP1 expression, either through the addition of shikonin or exposure to hypoxia (Supplementary Figs. S4A-S4D), might inhibit the import of DNA repair-associated enzymes $[49,52]$ such as ATM and gamma-H2AX, as well as that of mitochondrial biogenesis- and oxidative respiration-related proteins to decrease genomic and mitochondrial DNA stability, which is ultimately reflected in an increased sensitivity to drugs and radiation.

Autophagy is generally regarded as a rescue response in both normal cells and tumor cells confronted with various forms of danger, such as starvation and irradiation exposure. We found that the inhibition of DRP1 significantly increased the radiation sensitivity and repressed the autophagy response of cells subjected to chemo-treatment (Figs. 3AB, 4C), while at the same time, DRP1-KD led to an increase in the apoptosis response of glioblastoma cells (Fig. 4D). Obviously, the lack of DRP1 similar to the inhibition of autophagy, contributed to the sensitivity of cells to both chemo- and radiotherapy [58]. In spite of the fact that this study could not clearly explain the role played by DRP1 in the autophagy process, it revealed evidence indicating that DRP1 is likely to play a role in mitochondrial DNA stability (Fig. 4E) [58].

\section{Conclusions}

In conclusion, our results showed that DRP1 is overexpressed in GBM, while the inhibition of DRP1 expression induces autophagy and enhances radiation sensitivity. This effect is specific to cancer cells, which overexpress not only DRP1 but also ATAD3A, AKR1C1, eukaryotic elongation factor (eEF2), and optic atrophy 1 (OPA1), phenomena which are not detected in their non-tumor counterparts $[34,59,60]$. In 
fact, this is the first report on the DRP1 expression and clinical characteristics of a large series of highgrade glioma patients. In addition to inducing autophagy, the silencing of DRP1 was found to reduce cell growth and invasion potentials, and such features were also found in GBM stem cells. Reducing DRP1 expression augmented the cytotoxicity of SAHA (acetylation and apoptosis-inducing agent) and daunorubicin as well. Although the population size of this study was small, our data shed some light on the radio-resistant phenotype of GBM, of which DRP1 could be a potential marker, even though DRP1 alone might not be an independent prognostic factor.

\section{List Of Abbreviations}

Abbreviations used are: ATAD3A, the ATPase family AAA domain containing 3A; CIM, confocal immunofluorescence microscopy; DRP1, dynamin-related protein 1; ER, endoplasmic reticulum; GBM, glioblastoma multiforme; hHR23A, human homolog of yeast Rad23 protein A; IDH1, isocitrate dehydrogenase 1; MAM, mitochondria-associated membrane; MGMT, $0^{6}$-methylguanine-DNAmethyltransferase; SAHA, suberoylanilide hydroxamic acid (vorinostat); TMZ, temozolomide; GSC, glioblastoma stem cells.

\section{Declarations Section}

Ethics approval and consent to participate: The protocols of this study were approved by the Medical Ethics Committee of Taichung Veterans General Hospital (Approval number: CF12026B\#2). The obtained samples were frozen immediately after surgery with prior consent from the patients. The validation cohort consisted of 47 cases selected from the primary cohort based on the following criteria: (1) available follow-up data and samples and (2) a post-operative survival time of more than 1 month. From January 2008 to August 2012, tissue specimens were collected from 47 patients with newly diagnosed GBM. Exclusion criteria: 1. GBM patients with unconfirmed pathology, 2. GBM patients with spinal involvement, 3. GBM patients with incomplete data records.

Consent for publication: Not applicable.

Availability of data and materials: All relevant data have been uploaded to DRYAD and can be accessed using the following link: https://datadryad.org/review?d oi = doi $\varangle 10.5061 /$ dryad.d025q4p

Competing Interests: This work was partly supported by the Comprehensive Academic Promotion Projects (NCHU 1025025, Ministry of Education, Taiwan) and the Ministry of Education, Taiwan, ROC, under the ATU plan, as well as by clinical research grants from Taichung Veteran General Hospital (101DHA0500377), Taichung, Taiwan; the Department of Health, Executive Yuan, Taipei, Taiwan (DOH102-TD-C-111-005), which was given to the China Medical University Hospital's Excellence in Cancer Research program, Taichung, Taiwan; and the National Science Council (NSC 102-2320-B-005-006), Taipei, Taiwan. The funders had no role in the study design, data collection, and analysis, decision to 
publish, or preparation of the manuscript. None of the authors received a salary from the above funders. All of the authors declare no conflicts of interest.

\section{Funding}

The funders had no role in the study design, data collection and analysis, decision to publish, or preparation of the manuscript.

\section{Authors' Contributions}

Conception and design: WC, KC, CS; Development of methodology: KC; Acquisition of data: WC, CS; Analysis and interpretation of data: WC, MC, YY, KC; Writing and review: WC, KC, CS; Administrative, technical, or material support: WC, KC. All authors read and approved the manuscript.

\section{Acknowledgement}

Not Applicable.

Author details: ${ }^{1}$ Institute of Biomedical Sciences, National Chung Hsing University, Taichung, Taiwan;

${ }^{2}$ Division of Minimally Invasive Neurosurgery, Neurological Institute, Taichung Veterans General Hospital, Taichung 40705, Taiwan; ${ }^{3}$ Department of Physical Therapy, Hung Kuang University, Taichung 43302, Taiwan; ${ }^{4}$ Graduate Institute of Biomedical Sciences, and ${ }^{5}$ Agricultural Biotechnology Centre, National Chung Hsing University, Taichung, Taiwan; ${ }^{6}$ Department of Medicine, and Graduate Institute of Medical Sciences, National Defence Medical Centre, Taipei, Taiwan; ${ }^{7}$ Tri-Service General Hospital, National Defence Medical Centre, Taipei, Taiwan; ${ }^{8}$ Department of Game and Product Design, Chienkuo Technology University, Taiwan; ${ }^{9}$ Basic Medical Education Center, Central Taiwan University of Science and Technology, Taichung, Taiwan. Wen-Yu Cheng 1,2,3, e-mail: wycheng07@yahoo.com.tw; Kuan-Chih Chow 4,5, e-mail: kcchow@dragon.nchu.edu.tw; Ming-Tsang Chiao ${ }^{2}$, e-mail: mtchiao@gmail.com; Yi-Chin Yang 2, e-mail: jean1007@gmail.com; Chiung-Chyi Shen *2,3,6,7,8,9, e-mail: ccshen61093@gmail.com

\section{References}

1. Jaoude DA, Moore JA, Moore MB, Twumasi-Ankrah P, Ablah E, Moore DF, Jr.: Glioblastoma and Increased Survival with Longer Chemotherapy Duration. Kans J Med 2019, 12(3):65-69.

2. Ohgaki H, Kleihues P: The definition of primary and secondary glioblastoma. Clin Cancer Res 2013, 19(4):764-772.

3. Stupp R, Hegi ME, Mason WP, van den Bent MJ, Taphoorn MJ, Janzer RC, Ludwin SK, Allgeier A, Fisher $\mathrm{B}$, Belanger $\mathrm{K}$ et al: Effects of radiotherapy with concomitant and adjuvant temozolomide versus radiotherapy alone on survival in glioblastoma in a randomised phase III study: 5-year analysis of the EORTC-NCIC trial. Lancet Oncol 2009, 10(5):459-466. 
4. Shinojima N, Tada K, Shiraishi S, Kamiryo T, Kochi M, Nakamura H, Makino K, Saya H, Hirano H, Kuratsu $\mathrm{J}$ et al: Prognostic value of epidermal growth factor receptor in patients with glioblastoma multiforme. Cancer Res 2003, 63(20):6962-6970.

5. Sanson M, Marie Y, Paris S, Idbaih A, Laffaire J, Ducray F, El Hallani S, Boisselier B, Mokhtari K, Hoang-Xuan $\mathrm{K}$ et al: Isocitrate dehydrogenase 1 codon 132 mutation is an important prognostic biomarker in gliomas. J Clin Oncol 2009, 27(25):4150-4154.

6. Ichimura K, Schmidt EE, Goike HM, Collins VP: Human glioblastomas with no alterations of the CDKN2A (p16INK4A, MTS1) and CDK4 genes have frequent mutations of the retinoblastoma gene. Oncogene 1996, 13(5):1065-1072.

7. Wang SI, Puc J, Li J, Bruce JN, Cairns P, Sidransky D, Parsons R: Somatic mutations of PTEN in glioblastoma multiforme. Cancer Res 1997, 57(19):4183-4186.

8. Fulci G, Labuhn M, Maier D, Lachat Y, Hausmann O, Hegi ME, Janzer RC, Merlo A, Van Meir EG: p53 gene mutation and ink4a-arf deletion appear to be two mutually exclusive events in human glioblastoma. Oncogene 2000, 19(33):3816-3822.

9. Spiegl-Kreinecker S, Pirker C, Filipits M, Lotsch D, Buchroithner J, Pichler J, Silye R, Weis S, Micksche $\mathrm{M}$, Fischer $\mathrm{J}$ et al: 06-Methylguanine DNA methyltransferase protein expression in tumor cells predicts outcome of temozolomide therapy in glioblastoma patients. Neuro Oncol 2010, 12(1):28-36.

10. Efird JT, Friedman GD, Sidney S, Klatsky A, Habel LA, Udaltsova NV, Van den Eeden S, Nelson LM: The risk for malignant primary adult-onset glioma in a large, multiethnic, managed-care cohort: cigarette smoking and other lifestyle behaviors. J Neurooncol 2004, 68(1):57-69.

11. Hardell L, Carlberg M, Hansson Mild K: Epidemiological evidence for an association between use of wireless phones and tumor diseases. Pathophysiology 2009, 16(2-3):113-122.

12. Efird JT: Season of birth and risk for adult onset glioma. Int J Environ Res Public Health 2010, 7(5):1913-1936.

13. Baglietto L, Giles GG, English DR, Karahalios A, Hopper JL, Severi G: Alcohol consumption and risk of glioblastoma; evidence from the Melbourne Collaborative Cohort Study. Int J Cancer2011, 128(8):1929-1934.

14. Carlberg M, Hardell $L$ : On the association between glioma, wireless phones, heredity and ionising radiation. Pathophysiology 2012, 19(4):243-252.

15. Haas-Kogan DA, Prados MD, Tihan T, Eberhard DA, Jelluma N, Arvold ND, Baumber R, Lamborn KR, Kapadia $\mathrm{A}$, Malec $\mathrm{M}$ et al: Epidermal growth factor receptor, protein kinase B/Akt, and glioma response to erlotinib. J Natl Cancer Inst 2005, 97(12):880-887.

16. Huang TT, Sarkaria SM, Cloughesy TF, Mischel PS: Targeted therapy for malignant glioma patients: lessons learned and the road ahead. Neurotherapeutics 2009, 6(3):500-512.

17. Ohka F, Natsume A, Wakabayashi T: Current trends in targeted therapies for glioblastoma multiforme. Neurol Res Int 2012, 2012:878425.

18. Hu YL, DeLay M, Jahangiri A, Molinaro AM, Rose SD, Carbonell WS, Aghi MK: Hypoxia-induced autophagy promotes tumor cell survival and adaptation to antiangiogenic treatment in glioblastoma. 
Cancer Res 2012, 72(7):1773-1783.

19. Burton TR, Henson ES, Baijal P, Eisenstat DD, Gibson SB: The pro-cell death Bcl-2 family member, BNIP3, is localized to the nucleus of human glial cells: Implications for glioblastoma multiforme tumor cell survival under hypoxia. Int J Cancer 2006, 118(7):1660-1669.

20. Daido S, Kanzawa T, Yamamoto A, Takeuchi H, Kondo Y, Kondo S: Pivotal role of the cell death factor BNIP3 in ceramide-induced autophagic cell death in malignant glioma cells. Cancer Res 2004, 64(12):4286-4293.

21. Wise DR, Ward PS, Shay JE, Cross JR, Gruber JJ, Sachdeva UM, Platt JM, DeMatteo RG, Simon MC, Thompson CB: Hypoxia promotes isocitrate dehydrogenase-dependent carboxylation of alphaketoglutarate to citrate to support cell growth and viability. Proc Natl Acad Sci U S A 2011, 108(49):19611-19616.

22. Ward PS, Thompson CB: Metabolic reprogramming: a cancer hallmark even warburg did not anticipate. Cancer Cel/ 2012, 21(3):297-308.

23. Wang H, Cai S, Ernstberger A, Bailey BJ, Wang MZ, Cai W, Goebel WS, Czader MB, Crean C, Suvannasankha A et al: Temozolomide-mediated DNA methylation in human myeloid precursor cells: differential involvement of intrinsic and extrinsic apoptotic pathways. Clin Cancer Res 2013, 19(10):2699-2709.

24. Chiang YY, Chen SL, Hsiao YT, Huang CH, Lin TY, Chiang IP, Hsu WH, Chow KC: Nuclear expression of dynamin-related protein 1 in lung adenocarcinomas. Mod Pathol 2009, 22(9):1139-1150.

25. Sudhakar JN, Chow KC: Human RAD23 homolog A is required for the nuclear translocation of apoptosis-inducing factor during induction of cell death. Biol Cell 2014, 106(10):359-376.

26. Chen X, Yao JM, Fang X, Zhang C, Yang YS, Hu CP, Chen Q, Zhong GW: Hypoxia promotes pulmonary vascular remodeling via HIF-1alpha to regulate mitochondrial dynamics. J Geriatr Cardio/ 2019, 16(12):855-871.

27. Zhang D, Liu Y, Tang Y, Wang X, Li Z, Li R, Ti Z, Gao W, Bai J, Lv Y: Increased mitochondrial fission is critical for hypoxia-induced pancreatic beta cell death. PLoS One 2018, 13(5):e0197266.

28. Fang HY, Chang CL, Hsu SH, Huang CY, Chiang SF, Chiou SH, Huang CH, Hsiao YT, Lin TY, Chiang IP et al: ATPase family AAA domain-containing $3 \mathrm{~A}$ is a novel anti-apoptotic factor in lung adenocarcinoma cells. J Cell Sci 2010, 123(Pt 7):1171-1180.

29. Chiang SF, Huang CY, Lin TY, Chiou SH, Chow KC: An alternative import pathway of AlF to the mitochondria. Int J Mol Med 2012, 29(3):365-372.

30. Taguchi N, Ishihara N, Jofuku A, Oka T, Mihara K: Mitotic phosphorylation of dynamin-related GTPase Drp1 participates in mitochondrial fission. J Biol Chem 2007, 282(15):11521-11529.

31. Tacka KA, Szalda D, Souid AK, Goodisman J, Dabrowiak JC: Experimental and theoretical studies on the pharmacodynamics of cisplatin in jurkat cells. Chem Res Toxicol 2004, 17(11):1434-1444.

32. Qian W, Choi S, Gibson GA, Watkins SC, Bakkenist CJ, Van Houten B: Mitochondrial hyperfusion induced by loss of the fission protein Drp1 causes ATM-dependent G2/M arrest and aneuploidy through DNA replication stress. J Cell Sci 2012, 125(Pt 23):5745-5757. 
33. Hasnat M, Yuan Z, Naveed M, Khan A, Raza F, Xu D, Ullah A, Sun L, Zhang L, Jiang Z: Drp1associated mitochondrial dysfunction and mitochondrial autophagy: a novel mechanism in triptolide-induced hepatotoxicity. Cell Biol Toxicol 2019, 35(3):267-280.

34. Chen TC, Hung YC, Lin TY, Chang HW, Chiang IP, Chen YY, Chow KC: Human papillomavirus infection and expression of ATPase family AAA domain containing 3A, a novel anti-autophagy factor, in uterine cervical cancer. Int J Mol Med 2011, 28(5):689-696.

35. Huang KH, Chow KC, Chang HW, Lin TY, Lee MC: ATPase family AAA domain containing 3A is an anti-apoptotic factor and a secretion regulator of PSA in prostate cancer. Int J Mol Med 2011, 28(1):9-15.

36. Remmele W, Schicketanz KH: Immunohistochemical determination of estrogen and progesterone receptor content in human breast cancer. Computer-assisted image analysis (QIC score) vs. subjective grading (IRS). Pathol Res Pract 1993, 189(8):862-866.

37. Smith JS, Alderete B, Minn Y, Borell TJ, Perry A, Mohapatra G, Hosek SM, Kimmel D, O'Fallon J, Yates A et al: Localization of common deletion regions on $1 p$ and $19 q$ in human gliomas and their association with histological subtype. Oncogene 1999, 18(28):4144-4152.

38. Chiao MT, Cheng WY, Yang YC, Shen CC, Ko JL: Suberoylanilide hydroxamic acid (SAHA) causes tumor growth slowdown and triggers autophagy in glioblastoma stem cells. Autophagy 2013, 9(10):1509-1526.

39. Cheng WY, Chiao MT, Liang YJ, Yang YC, Shen CC, Yang CY: Luteolin inhibits migration of human glioblastoma U-87 MG and T98G cells through downregulation of Cdc42 expression and PI3K/AKT activity. Mol Biol Rep 2013, 40(9):5315-5326.

40. Ishiyama M, Tominaga $H$, Shiga M, Sasamoto K, Ohkura Y, Ueno K: A combined assay of cell viability and in vitro cytotoxicity with a highly water-soluble tetrazolium salt, neutral red and crystal violet. Biol Pharm Bull 1996, 19(11):1518-1520.

41. EL K, P M: Nonparamertric estimation form incomplete observations. j Am Stat Assoc 1958, 53(282):457-481.

42. N M: Evaluation of survival data and two new rank order statistics arising in its consideration. Cancer Chemother Rep 1966, 50(3):163-170.

43. Yi F, Du J, Ni W, Liu W: Tbx2 confers poor prognosis in glioblastoma and promotes temozolomide resistance with change of mitochondrial dynamics. Onco Targets Ther 2017, 10:1059-1069.

44. Wu J, Zhang B, Wuu YR, Davidson MM, Hei TK: Targeted cytoplasmic irradiation and autophagy. Mutat Res 2017, 806:88-97.

45. Steponkiene S, Kavaliauskiene S, Purviniene R, Rotomskis R, Juzenas P: Quantum dots affect expression of CD133 surface antigen in melanoma cells. Int J Nanomedicine 2011, 6:2437-2444.

46. Ma HI, Chiou SH, Hueng DY, Tai LK, Huang PI, Kao CL, Chen YW, Sytwu HK: Celecoxib and radioresistant glioblastoma-derived CD133+ cells: improvement in radiotherapeutic effects. Laboratory investigation. J Neurosurg 2011, 114(3):651-662. 
47. Chiang YY, Wang SL, Yang CL, Yang HY, Yang HC, Sudhakar JN, Lee CK, Huang HW, Chen CM, Chiou $\mathrm{SH}$ et al: Extracts of Koelreuteria henryi Dummer induce apoptosis and autophagy by inhibiting dihydrodiol dehydrogenase, thus enhancing anticancer effects. Int J Mol Med 2013, 32(3):577-584.

48. Park MN, Song HS, Kim M, Lee MJ, Cho W, Lee HJ, Hwang CH, Kim S, Hwang Y, Kang B et al: Review of Natural Product-Derived Compounds as Potent Antiglioblastoma Drugs. Biomed Res Int 2017, 2017:8139848.

49. You WC, Chiou SH, Huang CY, Chiang SF, Yang CL, Sudhakar JN, Lin TY, Chiang IP, Shen CC, Cheng WY et al: Mitochondrial protein ATPase family, AAA domain containing 3A correlates with radioresistance in glioblastoma. Neuro Oncol 2013, 15(10):1342-1352.

50. Deng HB, Parekh HK, Chow KC, Simpkins H: Increased expression of dihydrodiol dehydrogenase induces resistance to cisplatin in human ovarian carcinoma cells. J Biol Chem 2002, 277(17):1503515043.

51. Le Calve B, Rynkowski M, Le Mercier M, Bruyere C, Lonez C, Gras T, Haibe-Kains B, Bontempi G, Decaestecker $\mathrm{C}$, Ruysschaert JM et al: Long-term in vitro treatment of human glioblastoma cells with temozolomide increases resistance in vivo through up-regulation of GLUT transporter and aldo-keto reductase enzyme AKR1C expression. Neoplasia 2010, 12(9):727-739.

52. Lai TC, Chow KC, Fang HY, Cho HC, Chen CY, Lin TY, Chiang IP, Ho SP: Expression of xeroderma pigmentosum complementation group $C$ protein predicts cisplatin resistance in lung adenocarcinoma patients. Oncol Rep 2011, 25(5):1243-1251.

53. Oliva CR, Nozell SE, Diers A, McClugage SG, 3rd, Sarkaria JN, Markert JM, Darley-Usmar VM, Bailey SM, Gillespie GY, Landar A et al: Acquisition of temozolomide chemoresistance in gliomas leads to remodeling of mitochondrial electron transport chain. J Biol Chem 2010, 285(51):39759-39767.

54. Ambrose M, Goldstine JV, Gatti RA: Intrinsic mitochondrial dysfunction in ATM-deficient lymphoblastoid cells. Hum Mol Genet 2007, 16(18):2154-2164.

55. Kim WJ, Vo QN, Shrivastav M, Lataxes TA, Brown KD: Aberrant methylation of the ATM promoter correlates with increased radiosensitivity in a human colorectal tumor cell line. Oncogene 2002, 21(24):3864-3871.

56. Watters D, Kedar P, Spring K, Bjorkman J, Chen P, Gatei M, Birrell G, Garrone B, Srinivasa P, Crane DI et al: Localization of a portion of extranuclear ATM to peroxisomes. J Biol Chem 1999, 274(48):3427734282.

57. Baumgart E, Vanhorebeek I, Grabenbauer M, Borgers M, Declercq PE, Fahimi HD, Baes M: Mitochondrial alterations caused by defective peroxisomal biogenesis in a mouse model for Zellweger syndrome (PEX5 knockout mouse). Am J Pathol 2001, 159(4):1477-1494.

58. Bo T, Yamamori T, Suzuki M, Sakai Y, Yamamoto $K$, Inanami O: Calmodulin-dependent protein kinase II (CaMKII) mediates radiation-induced mitochondrial fission by regulating the phosphorylation of dynamin-related protein 1 (Drp1) at serine 616. Biochem Biophys Res Commun 2018, 495(2):16011607. 
59. Hsu NY, Ho HC, Chow KC, Lin TY, Shih CS, Wang LS, Tsai CM: Overexpression of dihydrodiol dehydrogenase as a prognostic marker of non-small cell lung cancer. Cancer Res 2001, 61(6):27272731.

60. Fang HY, Chen CY, Chiou SH, Wang YT, Lin TY, Chang HW, Chiang IP, Lan KJ, Chow KC: Overexpression of optic atrophy 1 protein increases cisplatin resistance via inactivation of caspasedependent apoptosis in lung adenocarcinoma cells. Hum Pathol 2012, 43(1):105-114.

\section{Supporting Information}

Supplementary Figure $\mathbf{S 1}$ Comparison of Kaplan-Meier product limit estimates of survival analysis in patients with GBM. Patients were divided into two groups based on DRP1 expression. Statistical differences in (A) overall and (B) progression-free survival between the two groups were compared using the log-rank test. Patients with higher DRP1 expression had significantly shorter overall survival (OS) ( $p=$ $0.0398,95 \%$ confidence interval $(\mathrm{Cl}), 1.051-8.151)$ and progression-free survival (PFS) $(p=0.0067 ; 95 \%$ $\mathrm{Cl}, 1.438-9.517 ; \mathrm{HR}, 3.699)$. When patients were grouped based on nuclear DRP1, the overall and progression-free survivals were respectively shown as (C) OS, $p=0.0039,95 \% \mathrm{Cl}, 1.448-6.93, \mathrm{HR}, 3.167$; and (D) PFS, $p<0.0001 ; 95 \% \mathrm{Cl}, 2.466-12.37 ; \mathrm{HR}, 5.523$. After MGMT status was listed as a perspective parameter, patients were divided into four groups. Statistical differences in the $(E)$ overall and $(F)$ progression-free survival among the four groups were compared using the log-rank test for trend. Patients with higher DRP1 expression and no MGMT promoter methylation had significantly shorter OS ( $p=$ $0.0141)$ and PFS $(p=0.0035)$.

Supplementary Figure S2 Characterization of 80- and 85-kDa DRP1-positive cells. (A) Western blotting analysis of T98G cell lysate with antibodies specific to DRP1. Molecular weights of both DRP1-positive protein bands were located between 70-kDa (red) and 100-kDa protein markers. (B) In the presence of calf intestinal phosphatase (CIP), the 85-kDa protein band gradually disappeared, but the levels of $80-k D a$ protein band increased, suggesting that the $85-\mathrm{kD}$ a protein could be a phosphorylated form of $80-\mathrm{kDa}$ DRP1. $\beta$-actin was used as an internal control to ensure that equal amounts of protein were added in each respective well. To validate the supposition that hypoxia could drive nuclear translocation of DRP1, cytoplasm and nuclei were separated by centrifugation prior to Western blotting. (C) Hypoxia increased cytoplasmic levels of 85-kDa DRP1. Moreover, hypoxia increased levels of both 80- and 85-kDa DRP1 in the nucleus. $\beta$-tubulin was used as cytoplasmic marker, and histone $\mathrm{H} 3$ was used as a nuclear marker to ensure that equal amounts of protein were added in each respective well. (D) Using reverse transcriptionpolymerase chain reaction (RT-PCR) to detect the expression of DRP1 mRNA in GBM cell lines and pathological specimens, we amplified a unique 678 base-pair (bp) band of amplified cDNA. The DNA fragments were excised from the gel and the sequences were verified to be DRP1 by DNA sequencing. 
Supplementary Figure S3 The effect of DRP1 expression on mitochondrial morphology of T98G cells. (A) The shape of mitochondria in untreated T98G cells (control). (B) In DRP1 gene-silenced cells (identified as DRP1-), most of the mitochondria became condensed, and some assumed an elongated shape. Vacuoles (arrow) and lysosome-like vesicles (white arrow) appeared in the cytoplasm, indicating a progression of autophagy. (C) In hypoxia-exposed T98G cells (with hypoxia exposure lasting for $48 \mathrm{hr}$, representing cells with nuclear DRP1, DRP1nuc), the mitochondria were elongated, but with a certain degree of swelling. However, some of the mitochondrial outer membranes were disintegrated and some of the internal contents were starting to leak out. (D) In shikonin-treated cells ( $24 \mathrm{hr}$ ), the mitochondria were highly condensed, and some of the vacuoles appeared right next to the mitochondria, suggesting an expansion of the mitochondria-associated membrane (MAM) and the initiation of autophagy.

Supplementary Figure S4 Shikonin and SAHA had different effects on the expression and intracellular localization of DRP1 as well as the radio-resistance of T98G cells. (A) Distribution of DRP1 as determined by immunofluorescence confocal microscopy. (A1) T98G cells were fed with MitoTracker green FM (mitochondria-specific dye, green fluorescence) before being stained with DRP1-specific monoclonal antibodies labeled with rhodamine (red fluorescence) and with DAPI (nuclear stain, blue fluorescence). (A2) Exposure to hypoxia for 48 hrs increased both cytoplasmic and nuclear DRP1 expression, in particular nucleolar DRP1 expression (red fluorescence), in T98G cells when compared to the control group. There results corresponded well with our previous study of lung adenocarcinomas (Chiang et al., 2009) and indicated that DRP1 was located on mitochondria. In the merged images, the yellow fluorescence showed the overlaps of red and green fluorescence at the same location. The purple nuclei reflected the overlaps of red and blue fluorescence. (A3) SAHA treatment for $48 \mathrm{hrs}$ reduced some of the nuclear DRP1 expression and increased apoptosis (as shown by the appearance of micronucleated cells, with white arrow heads pointed at the fragmented nuclei). (A4) Addition of shikonin for $24 \mathrm{hrs}$, on the other hand, reduced both cytoplasmic and nuclear levels of DRP1, but increased autophagic vacuoles (white arrows). (B) Pre-treatment with different concentrations of shikonin for 24 hrs increased radiation sensitivity of T98G cells. $\bigotimes$, control; $\varangle, 0.5 \mu \mathrm{M}$ shikonin; $\varangle, 2 \mu \mathrm{M}$ shikonin; $\varangle, 5 \mu \mathrm{M}$ shikonin. (C) Pretreatment with $5 \mu \mathrm{M}$ of SAHA for various periods of time (from 24-72 hrs) also decreased radiation resistance of T98G cells. $\otimes$, control; $\otimes$, pre-treatment for $24 \mathrm{hrs;} \otimes$, pre-treatment for $48 \mathrm{hrs;} \otimes$, pre-treatment for 72 hrs

Supplementary Figure $\mathbf{S} 5$ Controls of the immunohistochemical staining. (A) Pathological sections of lung adenocarcinoma tissue that had been stained positive for DRP1. (B) T98G cells that, were stained positive for DRP1 by immunocytochemistry. The cells were grown on slides and then fixed with acetone/methanol (50\%:50\%) at $4^{\circ} \mathrm{C}$ for 15 min before staining. Methyl green was used for counterstaining. (C) The negative control of immunohistochemical staining, in which antibodies specific to DRP1 were not added to the GBM sections. 


\section{Table}

Table 1. The correlations among DRP-1 expression and various patient characteristics.

\begin{tabular}{|c|c|c|c|c|c|}
\hline & $\begin{array}{c}\text { Patients } \\
(\mathrm{n}=47)\end{array}$ & $\begin{array}{c}\text { DRP-1nuc } \\
(\mathrm{n}=33)\end{array}$ & $\begin{array}{c}\text { DRP-1cyt } \\
(\mathrm{n}=8)\end{array}$ & $\begin{array}{c}\text { DRP-1- } \\
(n=6)\end{array}$ & $\begin{array}{c}p \\
\text { value }\end{array}$ \\
\hline & $\%$ & $\%$ & $\%$ & $\mathrm{n} \quad \%$ & \\
\hline$\overline{\text { Age }}$ & & & & & 0.534 \\
\hline$\leqq 60$ & 25 (53.2\%) & 18 (54.5\%) & $3(37.5 \%)$ & $4(66.7 \%)$ & \\
\hline$>60$ & $22(46.8 \%)$ & 15 (45.5\%) & $5(62.5 \%)$ & $2(33.3 \%)$ & \\
\hline Gender & & & & & 0.221 \\
\hline Male & 22 (46.8\%) & $16(48.5 \%)$ & $5(62.5 \%)$ & $1(16.7 \%)$ & \\
\hline Female & $25(53.2 \%)$ & $17(51.5 \%)$ & $3(37.5 \%)$ & $5(83.3 \%)$ & \\
\hline Tumor number & & & & & 0.101 \\
\hline Solitary & 43 (91.5\%) & $32(97.0 \%)$ & $6(75.0 \%)$ & $5(83.3 \%)$ & \\
\hline Multiple & $4(8.5 \%)$ & $1(3.0 \%)$ & $2(25.0 \%)$ & $1(16.7 \%)$ & \\
\hline Tumor size & & & & & 0.305 \\
\hline$\leqq 3 \mathrm{~cm}$ & $5(10.6 \%)$ & $5(15.2 \%)$ & $0(0.0 \%)$ & $0(0.0 \%)$ & \\
\hline$>3 \mathrm{~cm}$ & 42 (89.4\%) & 28 (84.8\%) & $8(100.0 \%)$ & $6(100.0 \%)$ & \\
\hline $\begin{array}{l}\text { Tumor } \\
\text { occurrence }\end{array}$ & & & & & 0.177 \\
\hline Primary & 41 (87.2\%) & 29 (87.9\%) & $8(100.0 \%)$ & $4(66.7 \%)$ & \\
\hline Recurrence & $6(12.8 \%)$ & $4(12.1 \%)$ & $0(0.0 \%)$ & $2(33.3 \%)$ & \\
\hline
\end{tabular}

\section{Figures}



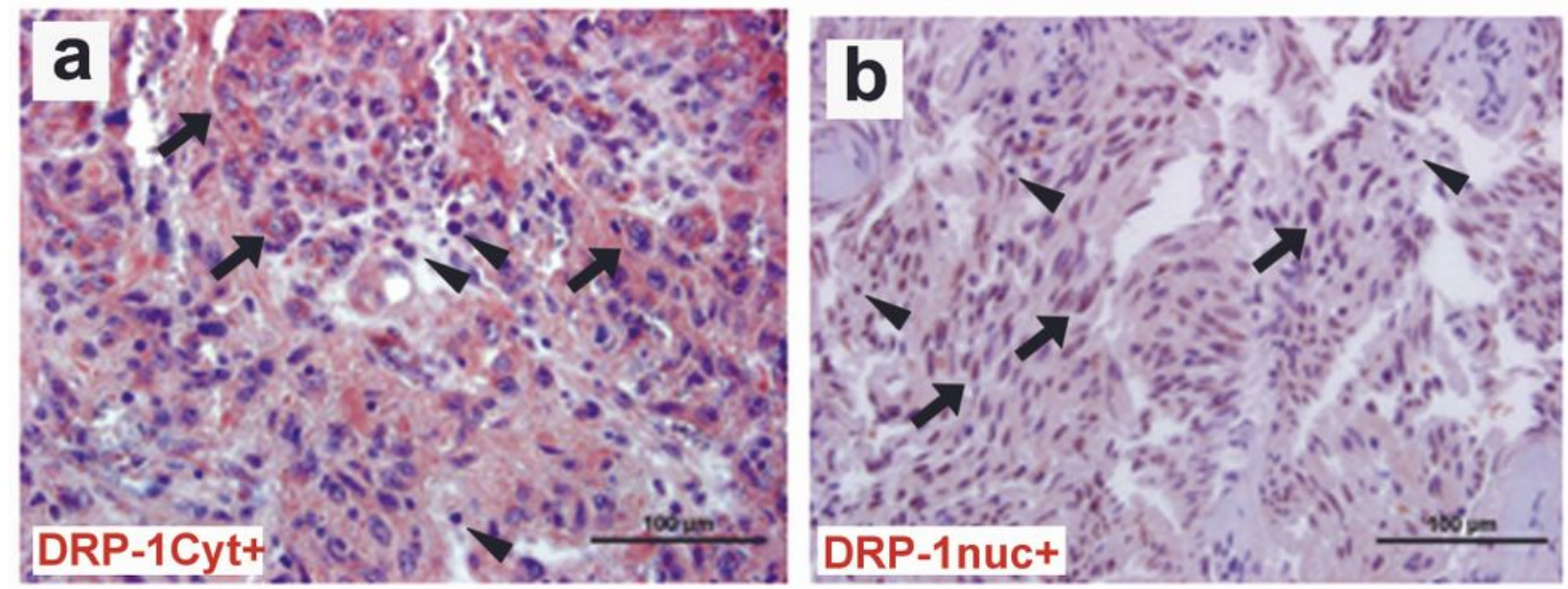

C

\section{Sample number}
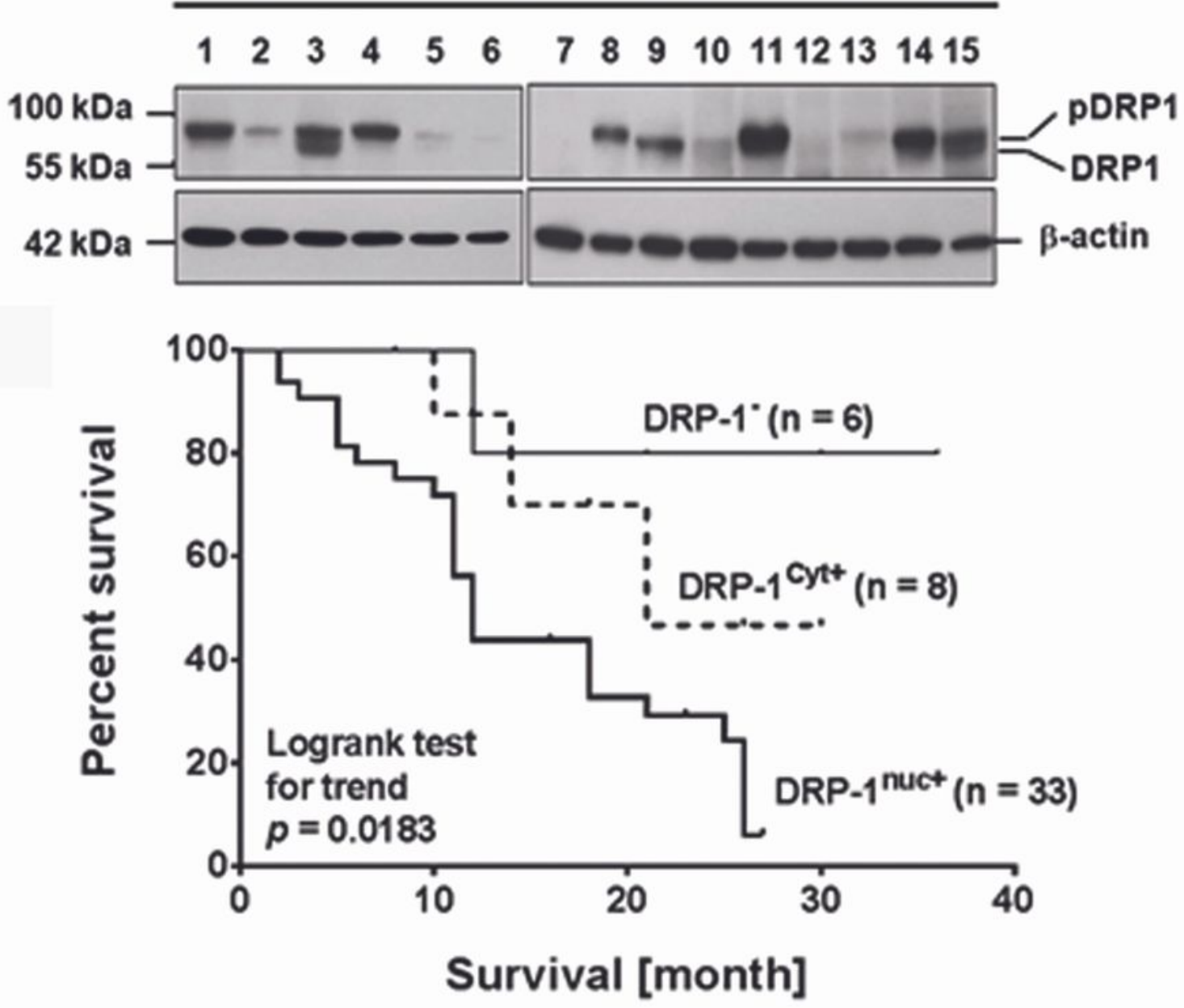

Figure 1

Immunohistochemical staining for the detection of DRP1 expression in GBM pathological specimens. In Taiwanese patients, (A) GBM tumor tissues highly expressed DRP1 (shown as crimson precipitates in the cytoplasm, denoted as DRP1 cyt+) and (B) highly expressed nuclear DRP1 (shown as brown precipitates in the nuclei, denoted as DRP1 nuc+) (original magnification $₫ 400$ ). The slides were counterstained with hematoxylin. (The positive and negative controls are shown in the Supplementary Figs. S5A-S5C) The 
black arrows indicate DRP1 staining in tumor cells. The white arrowheads indicate the infiltration of immune cells. Scale bars are $100 \mathrm{\square m}$. (C) Expression levels of DRP1 in surgically resected GBM specimens as determined by Western blotting. The calculated molecular weight of DRP1 was 80-kDa, and the 85-kDa protein bands were probably the phosphorylated DRP1. (D) Comparison of Kaplan-Meier product limit estimates of survival analysis in patients with GBM. Patients were divided into three groups, DRP1nuc+ DRP1 cyt+ and DRP1-, according to the expression and location of DRP1. The statistical differences in survival among the three groups were compared using the log-rank test for trend. DRP1nuc+ patients (higher nuclear DRP1 expression) had significantly shorter OS $(p=0.0183)$. (For other survival comparisons, please check Supplementary Figs. S1A S1E). 

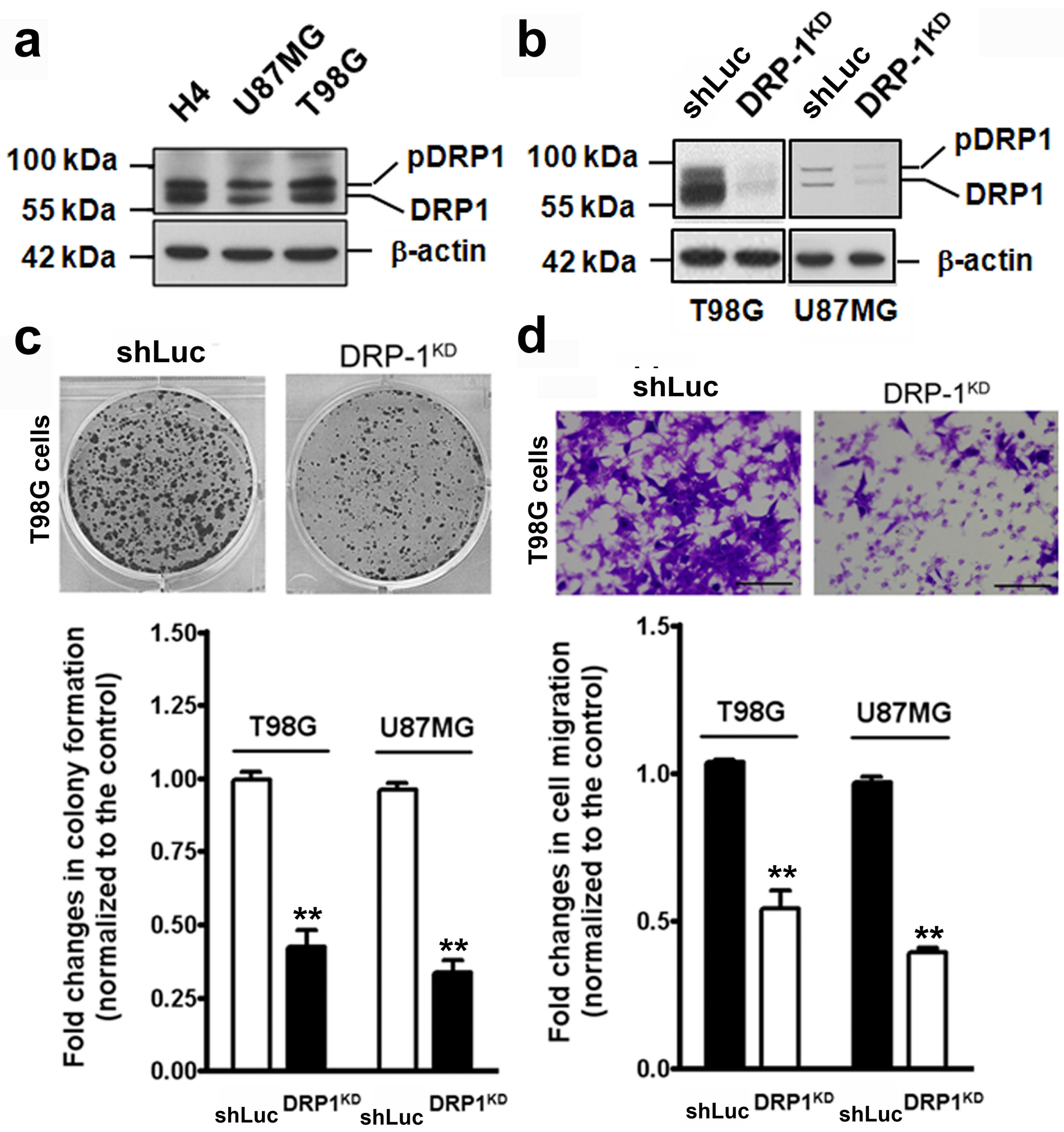

Figure 2

Correlation of DRP1 expression with cell growth and invasion potential of GBM cells. (A) DRP1 was highly expressed in human H4 and T98G glioblastoma cells. DRP1 level in U87MG cells was lower than that in T98G cells. (B) The silencing of DRP1 expression (DRP1KD) reduced the DRP1 protein levels (as detected by Western blotting) of the T98G cells and U87MG cells. (C) The silencing of DRP1 expression decreased proliferation capacity (as measured by colony formation). T98G cells are used as a 
representative. (D) DRP1KD T98G cells and DRP1KD U87MG cells had lower invasion potential (as measured by Matrigel penetration assay). T98G cells are used as a representative. Scale bars are $250 \square \mathrm{m}$. The results are presented as the means \pm S.D. of three independent experiments. ${ }^{*}, p<0.001$

a

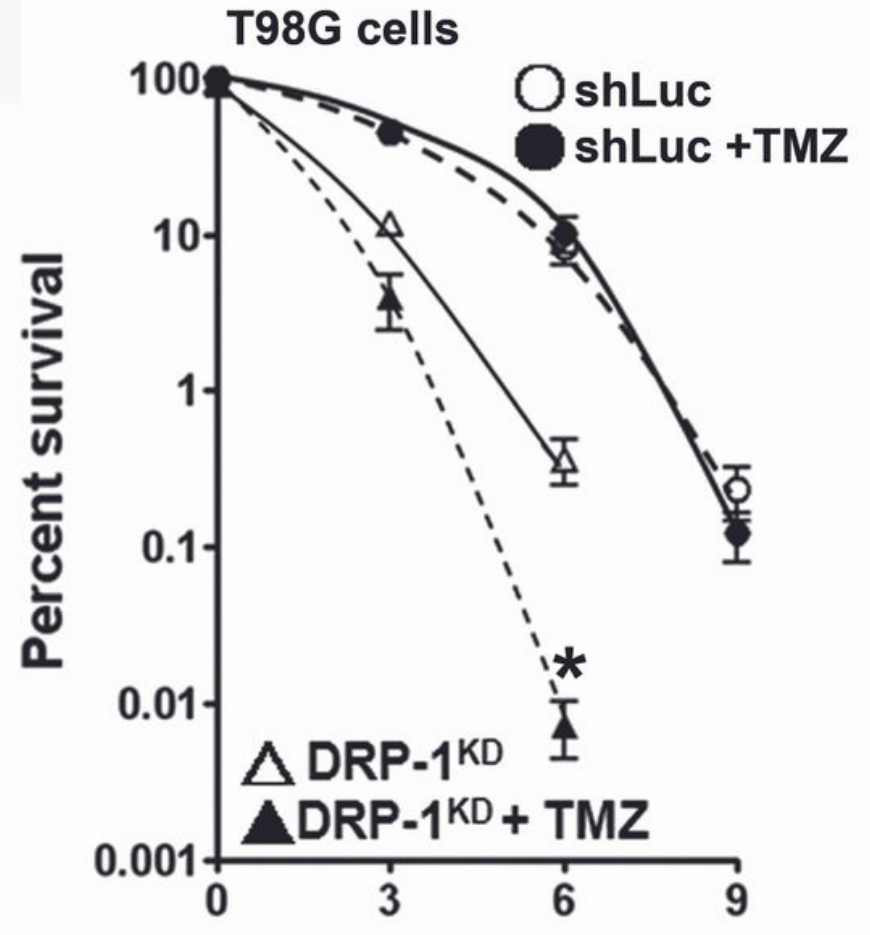

Radiation (Gy)

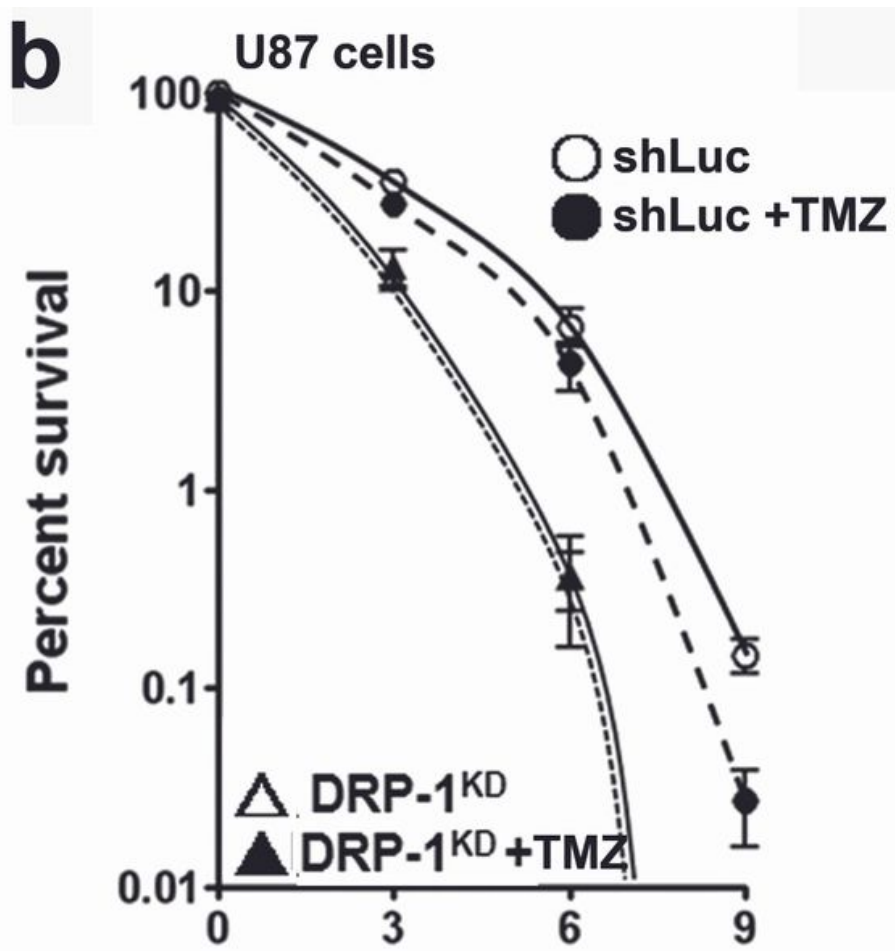

Radiation (Gy)

C
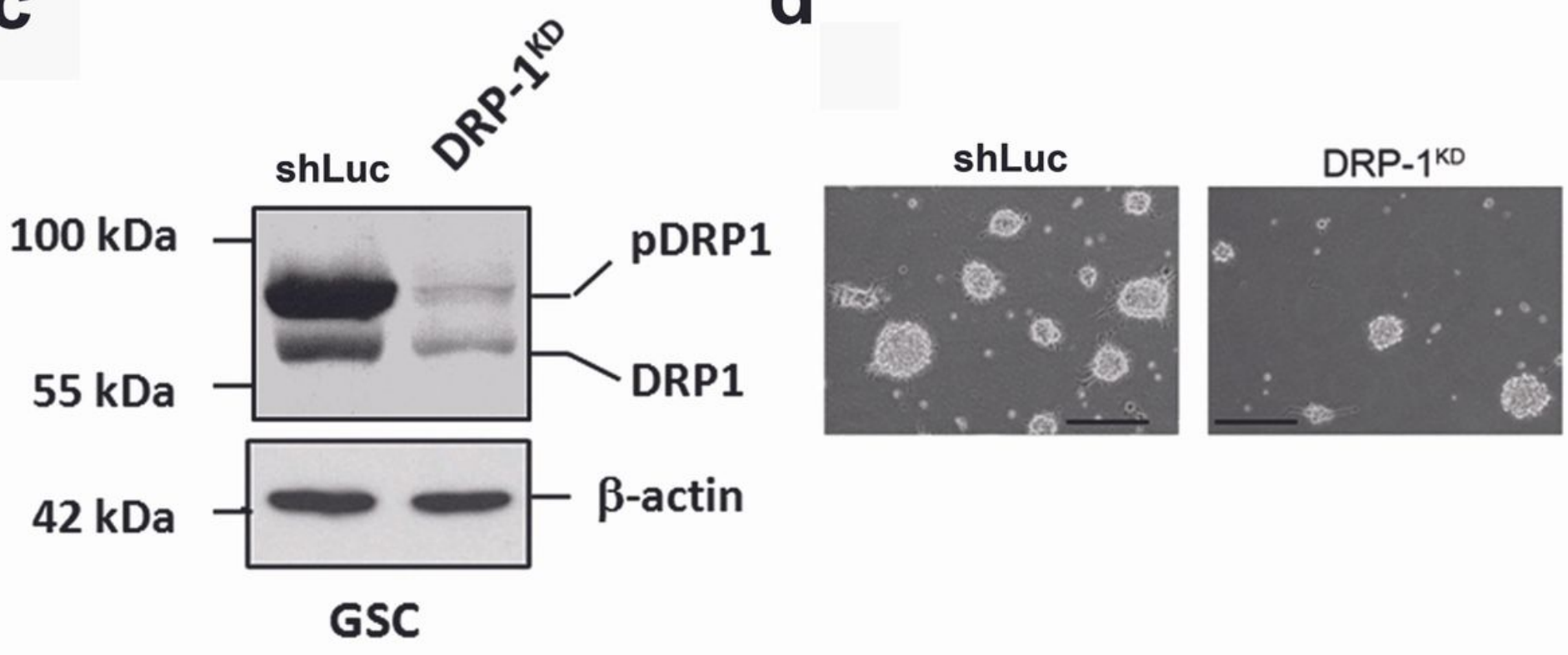

Figure 3

Correlation of DRP1 expression with radiation sensitivity of GBM and proliferation efficiency of GBM stem cells. (A) The silencing of DRP1 (DRP1KD) increased radiation-induced cell death (as measured by colony formation assay) in T98G cells. The addition of $50 \mathrm{CM} \mathrm{TMZ}$ did not affect the radiation resistance

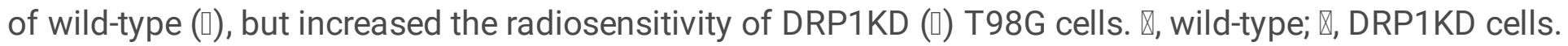




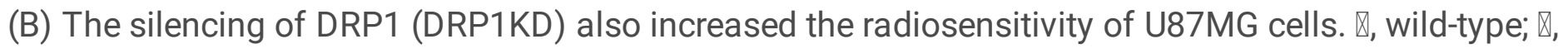
DRP1KD. TMZ reduced the radiation resistance of wild-type U87MG cells ( $\square$ ), but not of DRP1KD ( $\square$ ) cells. MGMT promoter in U87 cells is methylated, and that in T98G cells is unmethylated. Results are the means \pm S.D. of three independent experiments. ${ }^{*}, p<0.005$ (C) GBM stem cells highly expressed DRP1. The silencing of DRP1 expression (DRP1KD) reduced the DRP1 protein level (as detected by Western blotting). (D) DRP1KD GBM stem cells had lower proliferation ability (as measured by the formation of spheres). Scale bars are $250 \mathrm{Im}$. The results were repeated over three independent experiments in each case.

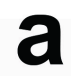

T98G cells

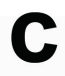

T98G cells
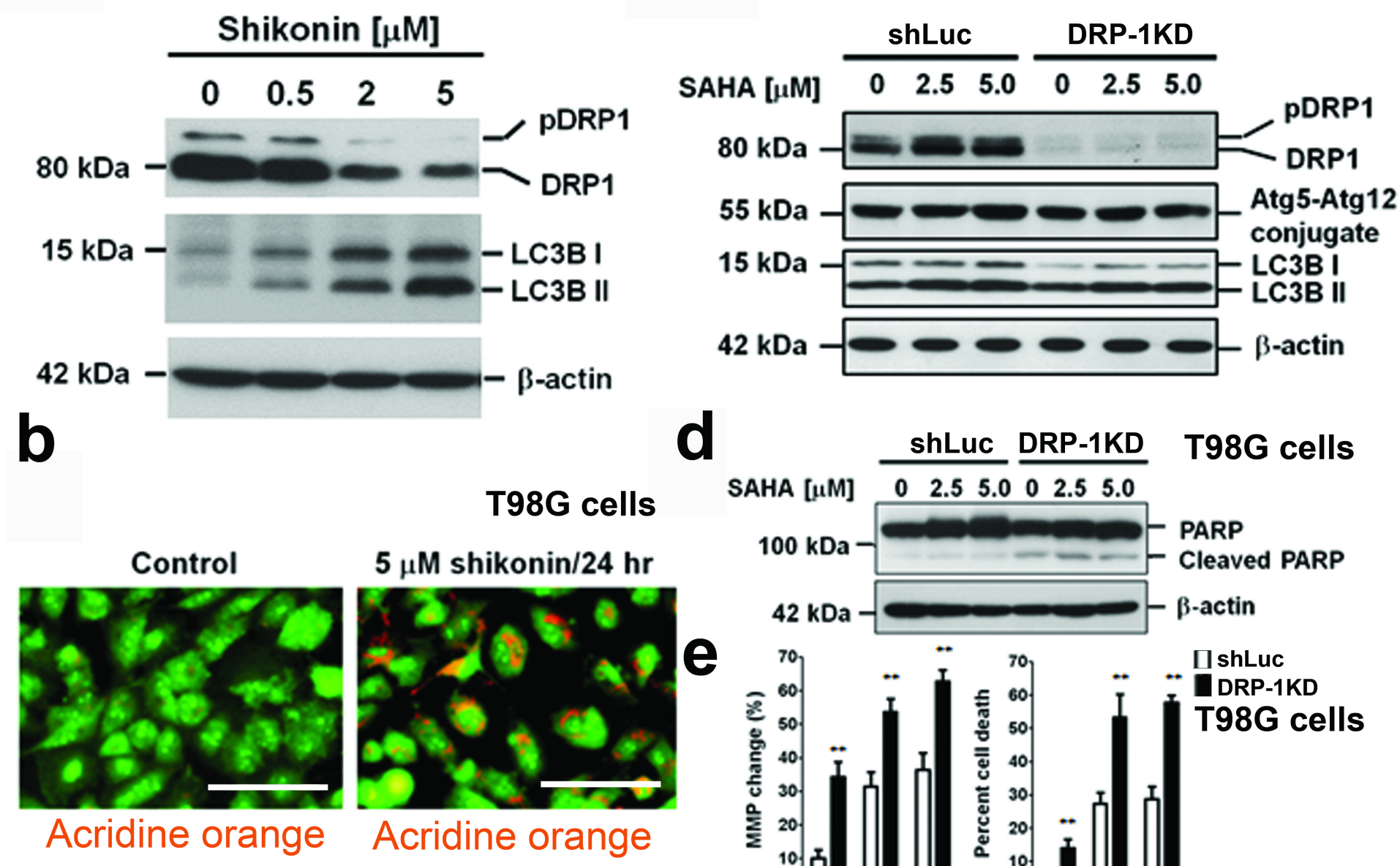

d

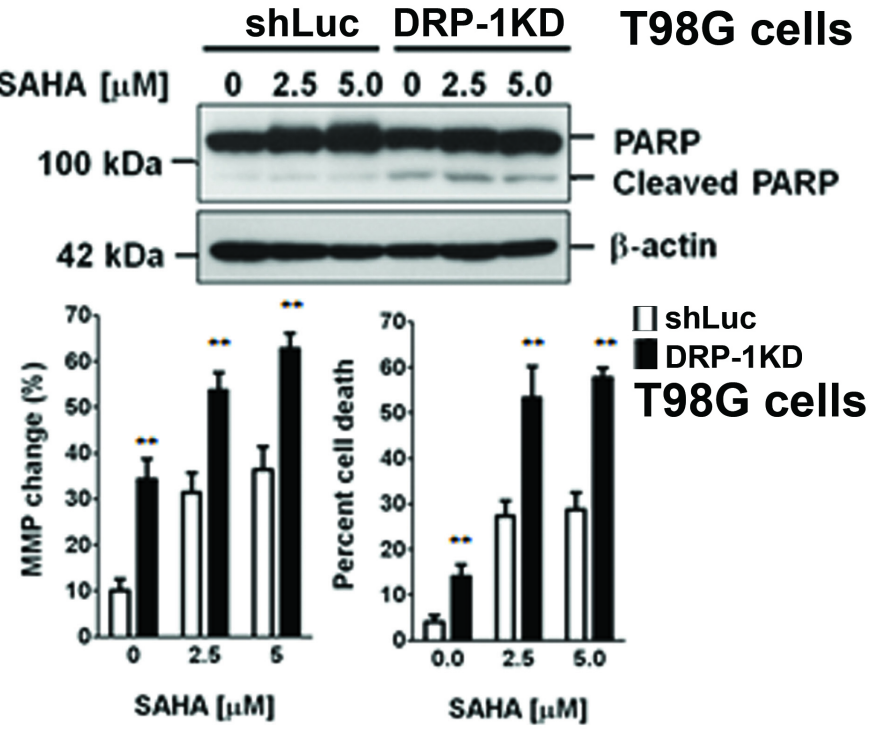

Figure 4

Shikonin and SAHA had different effects on gene expression of DRP1 in T98G cells. (A) The addition of shikonin inhibited expression of DRP1, and induced autophagy (as shown by increased levels of LC3B-II determined by Western blotting). (B) Treatment with shikonin for $24 \mathrm{hr}$ induced autophagy, as confirmed by the formation of autophagosomes, which was visualized by using fluorescence microscopy to detect the colour change of acridine orange (change from colorless to yellow or orange under low $\mathrm{pH}$ ). Scale 
bars are $100 \square \mathrm{m}$. (C) The addition of SAHA did not clearly affect DRP1 expression or induce autophagy (no obvious change of autophagy markers, ATg5-Atg12 conjugates and LC3B II, was detected by Western blotting). (D) Treatment with SAHA for $24 \mathrm{hr}$ did not readily induce cleavage of poly [ADP-ribose] polymerase 1 (PARP-1), a marker of apoptosis, but clearly increase PARP-1 levels (left side). In DRP1KD T98G cells, SAHA increased PARP-1 cleavage (right side). Expression of \-actin was used as a monitoring standard for relative protein expression in the Western blotting analysis. (E) Cell death, which was measured by colony formation assay, is presented in the right panel. Changes of mitochondrial membrane potential (MMP), an indication of mitochondria depolarization, is shown in the left panel. Briefly, following SAHA treatment, T98G cells were incubated with hydrophobic fluorescent dye 3,3'dihexyloxacarbocyanine iodide (DiOC6) at $37^{\circ} \mathrm{C}$ for 20 min prior to harvest. The collected cells were analyzed by the FACS Calibur (BD, CA, USA). Results are the means \pm S.D. of three independent experiments. **, $p<0.001$ 
a

\section{Shikonin Treatment (hr)}

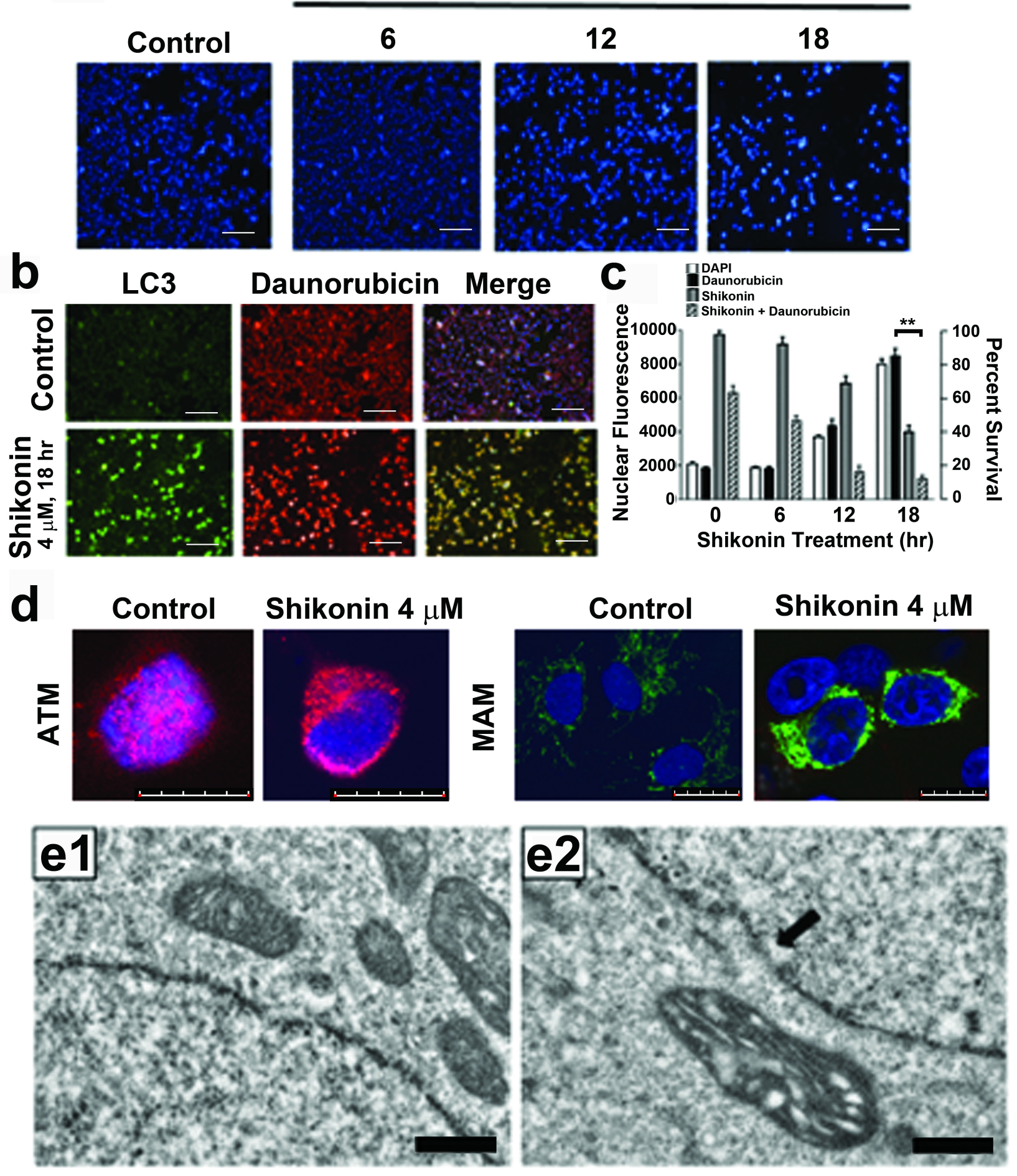

Figure 5

Shikonin increases nuclear levels of DAPI stain and an anticancer drug, daunorubicin, but inhibits nuclear transportation of a DNA repair-related protein, ATM. (A) 18-hr post-shikonin treatment, nuclear fluorescence of DAPI stain was increased by about 4 folds when T98G cells were scanned by an Operatta ${ }^{\circledR}$ imaging system. Scale bars are $250 \mathrm{Im}$. (B) Shikonin increased expression of LC3, an autophagy marker, in T98G cells. The LC3 signals were overlapped with the fluorescence of the 
anticancer drug daunorubicin when the cells were scanned by the Operatta ${ }^{\circledR}$ imaging system. Scale bars are $250 \square \mathrm{m}$. (C) A schematic composite of shikonin-treated cells. White column, cells stained with DAPI (as fluorescence control); black column, nuclear levels of daunorubicin; grey column, cytotoxicity of shikonin alone; slash-line column, cytotoxicity of shikonin and $0.5 \mathrm{\square M}$ daunorubicin, as measured by a WST-1 assay. The results were repeated over three independent experiments in each case. ${ }^{* *}, p<0.001$ (D) Shikonin inhibited the nuclear transportation of ATM (red fluorescence), and the proteins were accumulated in the enlarged MAM (green fluorescence), indicating that the decreasing expression of DRP1 also reduced the nuclear import of DNA repair-related proteins (You et al, 2013). Scale bars are 20 $\square \mathrm{m}$. The above results were repeated over three independent experiments in each case. (E) Compared to the control T98G cells (E1), shikonin induced damage of the nuclear envelopes (E2, arrow) when the cells were examined using a transmission electron microscope. Scale bars are $2.5 \square \mathrm{m}$.

\section{Supplementary Files}

This is a list of supplementary files associated with this preprint. Click to download.

- SupplementaryFigures.pdf

- SupplementaryFigures68.doc 